
\title{
educação revista
do centro de

\section{Formação em Educação: contribuições na prática pedagógica do egresso professor dos Institutos Federais do Brasil na área dos Saberes Técnicos}

Training in Education: contributions in the pedagogical practice of egress professor of Federal Institutes of Brazil in the area of Technical Knowledge

Lucila Maria Teixeira Nunes

Mestre pela Universidade Federal Rural do Rio de Janeiro, Seropédica, Rio de Janeiro, Brasil. lucilanunes96@gmail.com - http://orcid.org/0000-0003-0453-4301

Sandra Regina Gregorio

Professora Titular da Universidade Federal Rural do Rio de Janeiro, Seropédica, Rio de Janeiro,

Brasil.

gregorio.sandra@gmail.com - http://orcid.org/0000-0001-9935-3479

Gilmar Ferreira Vita

Pós-doutorando da Universidade Federal Rural do Rio de Janeiro, Seropédica, Rio de Janeiro, Brasil. gilmarferreiravita@yahoo.com.br - http://orcid.org/0000-0001-9479-6414

Recebido em 09 de novembro de 2018

Aprovado em 12 de setembro de 2019

Publicado em 09 de outubro de 2019

\section{RESUMO}

A presente pesquisa teve como objetivos caracterizar o perfil dos egressos da área de Ensino dos Saberes Técnicos do Programa de Pós-Graduação em Educação Agrícola (PPGEA), da Universidade Federal Rural do Rio de Janeiro (UFRRJ), docentes dos Institutos Federais de Educação, Ciência e Tecnologia do Brasil (IFECT), e reconhecer a contribuição do Programa no seu processo de formação e capacitação profissional. $O$ estudo foi de caráter descritivo-exploratório, quantitativo e qualitativo, realizado com uma população de 36 mestres. A metodologia utilizada foi levantamento de dados sobre os sujeitos, realizado na secretaria e website do Programa, e aplicação de questionário. Os resultados demonstraram que a maioria era oriunda da região Sudeste $(40,17 \%)$, formados em Ciências Agrícolas $(20,60 \%)$, e com tempo de docência acima de 15 anos (62,80\%). Com relação à atuação profissional, verificou-se que a maior parte lecionava para o Ensino Médio (48,20\%), atuando além da docência em atividades de pesquisa e extensão $(22,20 \%)$, e orientando alunos em programas de Iniciação Científica, projetos locais e organização de eventos $(61,10 \%)$. Após a conclusão do mestrado a totalidade dos egressos relatou aquisição de melhor conhecimento técnico $(41,30 \%)$, melhor remuneração $(33,30 \%)$ e maior confiança ao lecionar $(25,40 \%)$. Ficou estabelecido 


\section{Uism Eutlaghat}

ISSN: 1984-6444 | http://dx.doi.org/10.5902/1984644435565

ainda que o PPGEA vem alcançando suas metas no que concerne à construção do conhecimento e capacitação de seu egresso, confirmado por $100,00 \%$ dos informantes, quando afirmaram ter atingido suas expectativas parcial $(16,70 \%)$ ou plenamente $(83,30 \%)$.

Palavras-chave: Interdisciplinaridade; Transposição didática; Processo de ensinoaprendizagem.

\section{ABSTRACT}

The present research had as objectives to characterize the profile of the graduates of the area of Teaching of the Technical Knowledge of the Programa de PósGraduação em Educação Agrícola (PPGEA), of the Universidade Federal Rural do Rio de Janeiro (UFRRJ), professors of the Institutos Federais de Educação, Ciência e Tecnologia of the Brazil (IFECT), and recognize the Program's contribution to its professional training and qualification process. The study was descriptiveexploratory, quantitative and qualitative, carried out with a population of 36 masters. The methodology used was data collection on the subjects, carried out in the secretariat and website of the Program, and application of questionnaire. The results showed that the majority came from the Southeast region (40.17\%), graduated in Agricultural Sciences $(20.60 \%)$, and with teaching time over 15 years $(62.80 \%)$. With regard to the professional performance, it was verified that the majority taught to the High School (48.20\%), acting in addition to teaching in research and extension activities $(22.20 \%)$, and guiding students in Scientific Initiation programs, local projects and organization of events $(61.10 \%)$. After completing the master's program, all the graduates reported better technical knowledge $(41.30 \%)$, better remuneration $(33.30 \%)$ and greater confidence in teaching $(25.40 \%)$. It was also established that the PPGEA has reached its goals regarding the construction of knowledge and training of its egress, confirmed by $100.00 \%$ of the informants, when they stated that reached their partial expectations (16.70\%) or fully (83.30\%).

Keywords: Interdisciplinarity; Didactic transposition; Teaching-learning process.

\section{Introdução}

A busca incessante pelo conhecimento, a natural evolução e as revoluções tecnológicas pelas quais os anos do século XX passaram, reiteraram a necessidade de se formar profissionais capacitados e qualificados para o mundo do trabalho, seja em ambiente acadêmico ou profissional. No entanto, para que ocorra tal capacitação, os docentes responsáveis também devem se preocupar com a busca constante em aperfeiçoar seu conhecimento e prática pedagógica (SELLES, 2002; 


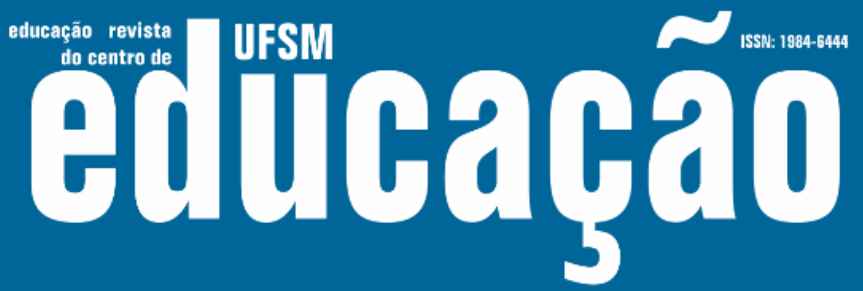

ISSN: 1984-6444 | http://dx.doi.org/10.5902/1984644435565

SANTOS, 2006; BATISTA, 2011).

Professores oriundos de áreas específicas precisam pensar reflexivamente sobre sua formação, pois apresentar títulos acadêmicos e especializações nem sempre são sinônimos de um bom professor ou de um desempenho satisfatório como docente. A simples transmissão do conhecimento não exige professor, visto que as novidades eletrônicas o fazem de forma atraente. A educação se dá quando professor e alunos constroem e participam do processo, havendo um contato pedagógico (DEMO, 2009; GARCIA, 2013).

A Educação Profissional Agrícola foi instituída como alvo para a atuação do Programa de Pós-Graduação em Educação Agrícola (PPGEA), da Universidade Federal Rural do Rio de Janeiro (UFRRJ). Desta forma, professores das áreas de Ensino dos Saberes Técnicos dos Institutos Federais de Educação, Ciência e Tecnologia do Brasil (IFECT), com a oportunidade de se dedicarem à formação continuada, escolheram tal Programa com o intuito de conhecer e ultrapassar os limites de sua atuação como docente. Na verdade, a formação do docente para o Ensino Agrícola deve privilegiar um profissional crítico, criativo, capaz de um pensar científico e de problematizar a realidade em que vive e convive.

No universo acadêmico, os cursos que oferecem habilitações para o bacharelado não apresentam em seu conteúdo disciplinas que enfocam a docência. Assim, questões relativas ao ensino e à aprendizagem de forma didática não são exploradas como em cursos de licenciatura. Sabe-se que o conhecimento aprendido e transposto para o aluno dentro de qualquer disciplina, principalmente na do professor da área de Ensino dos Saberes Técnicos, deve ser efetivo, promovendo a integração técnico-científica nos domínios educacionais. E ainda, acredita-se que um professor pode ser bom tanto nas esferas técnica e científica quanto na pedagógica (PARO, 2006; GOMES, 2011).

A educação profissional tem vivido grandes transformações que nos desafiam a organizar o trabalho pedagógico com alternativas inerentes à realidade. Em áreas como a Educação, é muito comum que os pós-graduandos já tenham formação e experiência docentes antes do ingresso no mestrado ou no doutorado. Mas pouco se sabe sobre as repercussões da pós-graduação nas suas práticas pedagógicas. 


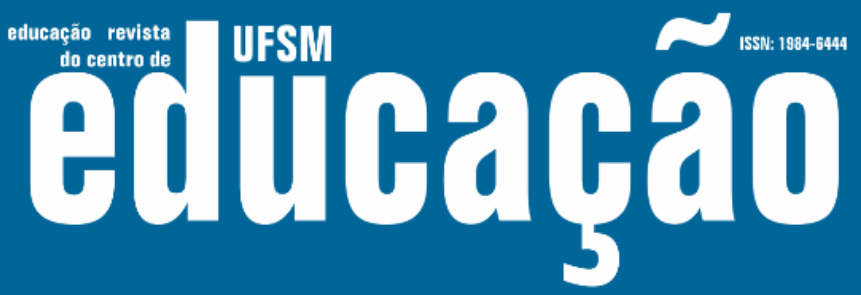

ISSN: 1984-6444 | http://dx.doi.org/10.5902/1984644435565

Buscando compreender melhor este universo da relação entre a formação do professor e suas práticas pedagógicas, neste trabalho elaborou-se como problema de estudo, conhecer a existência de contribuições na ação docente de professores da área de Ensino dos Saberes Técnicos, a partir da sua formação continuada em Educação Agrícola. Dentro deste preceito, buscamos na proposta do PPGEA/UFRRJ, identificar e analisar transposições pedagógicas de professores nas subáreas de Ensino dos Saberes Técnicos dos Institutos Federais atendidos por este programa de pós-graduação, por um período de 10 anos, compreendendo o período de 2005 a 2013.

Neste sentido, esta pesquisa teve como objetivos caracterizar o perfil dos egressos da área de Ensino dos Saberes Técnicos do PPGEA/UFRRJ, professores dos Institutos Federais, em nível de Brasil, e reconhecer através da percepção dos egressos, a contribuição do PPGEA no seu processo de formação e capacitação profissional.

\section{Metodologia}

A pesquisa foi desenvolvida no Programa de Pós-Graduação em Educação Agrícola (PPGEA), Instituto de Agronomia, Universidade Federal Rural do Rio de Janeiro (UFRRJ), localizado no município de Seropédica, estado do Rio de Janeiro, no período de 2013 a 2015.

Caracteriza-se como pesquisa quali-quantitativa, exploratória-descritiva, de recorte transversal e tipo pura ou fundamental. Para Godoy (1995) a pesquisa qualitativa serve para estudar os fenômenos que envolvem os seres humanos e suas intrincadas relações sociais, estabelecidas em diversos ambientes. Numa pesquisa qualitativa o propósito não deve ser contabilizar quantidades, mas sim compreender o comportamento de determinado grupo em estudo (CRESWELL, 2007). Michel (2009) descreveu a pesquisa quantitativa como um método de pesquisa social que utiliza a quantificação nas modalidades de coleta de informações e no seu tratamento, utilizando técnicas estatísticas, entre outras, percentual, média, desvio-padrão, coeficiente de correlação e análise de regressão. 


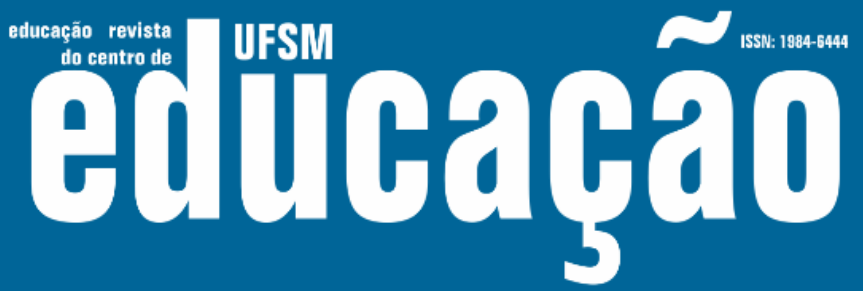

ISSN: 1984-6444 | http://dx.doi.org/10.5902/1984644435565

Gil (2008) e Creswell (2007) definiram exploratória por tratar de um tema ainda pouco explicado teoricamente, e descritiva por estar fundamentada na pesquisa qualitativa, que é por princípio, descritiva. Assim, é exploratória-descritiva por trazer à tona um estudo ainda em fase de exploração no meio acadêmico, com base na descrição de uma realidade estudada. De acordo com Richardson (2018), uma pesquisa de recorte transversal parte de dados coletados em um ponto no tempo, com base em uma amostra selecionada para descrever uma população nesse determinado momento. Dessa maneira, identifica-se a população relevante, escolhese a amostra e realiza-se a pesquisa. Já Gil (2008) classifica uma pesquisa tipo pura ou fundamental, como aquela que busca o progresso científico e a ampliação do seu conhecimento sem a preocupação de utilizá-los na prática.

Os sujeitos da pesquisa constituem o universo de egressos da área de Ensino dos Saberes Técnicos do PPGEA/UFRRJ, que concluíram o curso de mestrado acadêmico no período compreendido entre 2005 e 2013, e que atuam como docentes das unidades dos Institutos Federais de Educação, Ciência e Tecnologia (IFECT) de todo o país.

O PPGEA/UFRRJ apresenta duas áreas de concentração, Ensino em Educação e Gestão e Ensino dos Saberes Técnicos. A segunda área é dividida em quatro subáreas de conhecimento, classificadas em Ensino em Meio Ambiente, Ensino em Produção Vegetal, Ensino em Produção animal e Ensino em Agroindústria (PPGEA, 2018).

Considerando o período do levantamento de 2005 a 2013, apurou-se através de consulta em atas de defesa existentes na secretaria e em dissertações dispostas no website do PPPGEA/UFRRJ, que o programa havia titulado 413 mestres em suas duas áreas de atuação (PPGEA, 2018). Fez-se então um recorte focando o grupo de docentes dos Institutos Federais matriculados na área de Ensino dos Saberes Técnicos do Programa. Logo, das 413 dissertações defendidas, após as exclusões da área de Ensino em Educação e Gestão, de técnicos e egressos da Demanda Social, encontrou-se uma população de 117 (28,33\%) egressos a serem pesquisados. 


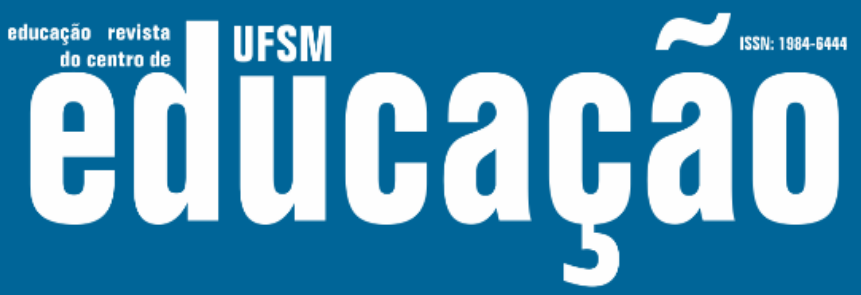

ISSN: 1984-6444 | http://dx.doi.org/10.5902/1984644435565

Os 117 egressos foram contatados através de e-mails de notificação, obtidos na secretaria do Programa. O conteúdo do texto continha instruções gerais sobre a pesquisa, que eram acompanhadas por um link que disponibilizava o acesso a um questionário. Este era autoaplicável, apresentando todas as informações necessárias para que os participantes da pesquisa pudessem respondê-lo sozinhos. Mesmo assim, a pesquisadora esteve à disposição para quaisquer esclarecimentos.

Quanto à forma das perguntas que compuseram o questionário, foram adotadas as três categorias gerais: questões abertas, fechadas e mistas, conforme definição apresentada por Marconi e Lakatos (2017a). O período estipulado para recebimento dos questionários preenchidos foi de julho a dezembro de 2014.

O questionário foi desenvolvido a partir do recurso do Google Drive (2018), que é uma ferramenta que disponibiliza variados procedimentos para a apresentação de uma pergunta. Esse banco de dados exporta automaticamente as informações sistematizadas para uma planilha eletrônica do programa Excel (Microsoft ${ }^{\circledR}$, Washington, USA), onde os dados foram organizados estatística e graficamente (MICROSOFT, 2018).

As respostas dadas pelos participantes foram analisadas de acordo com a sua natureza. Para as questões fechadas, foram tabuladas as frequências das respostas em cada categoria prevista e calculada a porcentagem de sua ocorrência. As questões abertas foram analisadas de acordo com o tema da questão, e as respostas encontradas foram agrupadas em categorias por similaridade, definindose, a seguir, as frequências dentro de cada categoria e calculando-se sua porcentagem de ocorrência (BARDIN, 2009).

Através de um termo de consentimento livre esclarecido (TCLE), foi solicitado a cada sujeito autorização para utilização dos dados declarados.

Dos 117 questionários enviados, somente 36 retornaram preenchidos e com acompanhamento do TCLE, ou seja, 30,77\%. Este resultado foi maior do que o observado por Marconi e Lakatos (2017b), que relataram como índice esperado de retorno cerca de $25,00 \%$. Uma possível justificativa para o baixo retorno foi que em alguns endereços eletrônicos os mesmos eram recebidos como spam (mensagem massificada não-solicitada). Para Bannan (2003) apud Gonçalves (2008), existe uma 


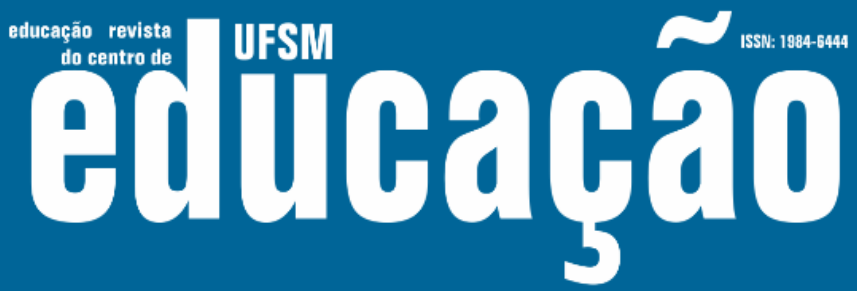

ISSN: 1984-6444 | http://dx.doi.org/10.5902/1984644435565

alta probabilidade da pesquisa pela internet ser percebida como spam.

Chaer et al. (2011) citaram que o questionário é um método que se usado corretamente transforma-se em um poderoso instrumento para obtenção de informações, possibilitando ao pesquisador desenvolver um estudo com padronização e uniformidade dos dados. Gil (2008) relaciona as vantagens da aplicação de questionário frente às outras técnicas utilizadas, e essas são: menores gastos, maior número de pessoas envolvidas, anonimato nas respostas, escolha do momento ideal para resolução e a livre opinião do questionado sem influência do entrevistador.

Antes da aplicação do questionário, foi efetuado um pré-teste a três egressos do referido Programa. Os resultados não foram utilizados, entretanto, foram importantes para assegurar a validade e precisão do questionário, permitindo realizar os devidos ajustes antes da sua aplicação, e possibilitando assim, que os sujeitos da pesquisa não tivessem dificuldades em responder às questões, discorrendo suas respostas de maneira a contribuir para o resultado do estudo.

O questionário foi elaborado em função da necessidade de se atingir os objetivos desta pesquisa, e para isso foram estabelecidos os seguintes indicadores: região geográfica de procedência do mestrando; formação acadêmica; tempo de docência; subárea de conhecimento selecionada; motivação que levou o egresso a cursar pós-graduação em nível de mestrado; motivos que levaram à escolha do PPGEA; atendimento das expectativas de formação dos mestrandos; lotação do egresso após passagem pelo PPGEA; continuidade na formação acadêmica; licença profissional para cursar o mestrado; contribuição do PPGEA para a atuação como docente; domínio e atualização dos professores do PPGEA; mudanças ocorridas após a conclusão do curso; função no Instituto Federal em consonância com a sua qualificação profissional; modalidade de ensino que atuam; atividades que desenvolve além das atividades de docência; estímulo à produção científica após o mestrado; publicação sobre sua dissertação em periódicos, livros ou outros; participação em eventos; e, orientação de alunos em iniciação científica. 


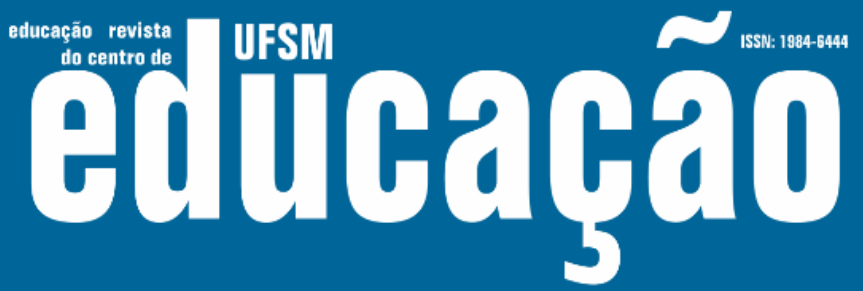

ISSN: 1984-6444 | http://dx.doi.org/10.5902/1984644435565

\section{Resultados e Discussão}

$\mathrm{Na}$ análise da literatura há poucos estudos que se propõem a avaliar o contexto aqui abordado, relativo ao acompanhamento de egressos de mestrado stricto sensu na área de Educação Agrícola, e ainda docentes de Institutos Federais nacionais; mas, dentro desse universo irrisório de publicações, procurou-se discutir e opinar sobre os diversos indicadores aqui convencionados.

Inicialmente, verificou-se a distribuição dos egressos da pesquisa por região geográfica do Brasil, o que evidenciou maiores percentuais na região Sudeste $(40,17 \%)$ e Nordeste (20,51\%) (Quadro 1). Bortolozzi e Gremski (2004) observaram que na região Sudeste encontravam-se 910 programas de pós-graduação, frente à região Sul (304), Nordeste (226), Centro-Oeste (88) e Norte (42). Guimarães et al. (2015), analisando a assimetria regional em função de programas de pós-graduação em Educação, relataram que mais de $60,00 \%$ desses encontravam-se na região Sudeste. Como existe uma estreita relação entre o número de programas e 0 número de acadêmicos, é evidente o maior contingente de mestres e doutores na região Sudeste. A Secretaria de Estado de Ciência, Tecnologia e Inovação de Pernambuco (SECTI, 2015), em boletim sobre indicadores em Ciência, Tecnologia e Inovação (CTI), enfatizou que a região Sudeste é a excelência da pós-graduação brasileira, e que o número de bolsas e de programas instalados, faz com que, naturalmente, a massa crítica de acadêmicos seja deslocada para essa região. Também, em virtude da maior probabilidade de ter acesso a uma melhor infraestrutura de pesquisa, ensino e aprendizagem, e à consequente valorização de seus currículos em relação às exigências do mercado.

Quanto à formação acadêmica dos egressos, ficou evidenciado durante este estudo, que a maioria provinha do curso de Ciências Agrícolas $(20,60 \%)$ e Ciências Biológicas (14,70\%) (Quadro 1). Esses resultados estão em concordância com Mendes et al. (2017), que analisando o perfil de ingressos no Programa de PósGraduação em Ambiente e Sistemas de Produção Agrícola, da Universidade do Estado de Mato Grosso, contabilizaram em 2013, maiores percentuais de mestrandos provindos da área de Agronomia (43,75\%) e da área de Ciências 


\section{Uism Eutbapga}

ISSN: 1984-6444 | http://dx.doi.org/10.5902/1984644435565

Biológicas (37,50\%). Foi notabilizado ainda neste indicador, a grande presença de mestrandos graduados na modalidade Licenciatura, o que demonstrou que os mesmos já adentraram no Programa apresentando em sua formação conceitos pedagógicos.

Quadro 1 - Perfil dos egressos do PPGEA/UFRRJ, da área de Ensino dos Saberes Técnicos, docentes dos Institutos Federais brasileiros, em seus indicadores, antecessores à realização do curso: região geográfica; curso de origem acadêmica; tempo de docência; e, motivação para cursar o mestrado.

\begin{tabular}{l|c}
\hline \multicolumn{1}{c|}{ Indicadores } & $\%$ \\
\hline Região geográfica & 40,17 \\
Sudeste & 20,51 \\
Nordeste & 15,38 \\
Centro-Oeste & 12,82 \\
Norte & 11,12 \\
Sul & \\
\hline Cursos de origem acadêmica & 20,60 \\
Licenciatura em Ciências Agrícolas & 14,70 \\
Ciências Biológicas & 11,9 \\
Licenciatura em Economia Doméstica & 8,9 \\
Medicina Veterinária & 5,9 \\
Enfermagem & 5,9 \\
Pedagogia & 5,9 \\
Administração de Empresas & 5,9 \\
Agronomia & 2,9 \\
Licenciatura em Geografia & 2,9 \\
Licenciatura em Química & 2,9 \\
Ciências Naturais & 2,9 \\
Nutrição & 2,9 \\
Engenharia de Alimentos & 2,9 \\
Tecnólogo em Gestão Ambiental & 2,9 \\
Tecnólogo em Irrigação e Drenagem & \\
\hline Tempo de docência & 11,50 \\
< 5 anos & 14,30 \\
6 a 10 anos & 11,40 \\
11 a 15 anos & 17,10 \\
16 a 20 anos & 17,10 \\
21 a 25 anos & 28,60 \\
$\geq 26$ anos & \\
\hline Motivação para cursar o mestrado & 28,60 \\
Aprimoramento Técnico-Científico & 23,50 \\
Evolução na carreira docente & 20,20 \\
Melhor remuneração & 17,60 \\
Satisfação pessoal & 10,10 \\
Reciclagem de conhecimento & \\
\hline Fonte: Autores. & \\
\hline & \\
\hline & \\
\hline & \\
\hline & \\
\hline
\end{tabular}




\section{Fusm Eulloahá}

ISSN: 1984-6444 | http://dx.doi.org/10.5902/1984644435565

Discorrendo sobre o tempo de docência do egresso pesquisado, observou-se que a maioria apresentava mais de 15 anos de professorado $(62,80 \%)$, o que certificava a experiência desses profissionais (Quadro 1). A obtenção deste dado foi importante, porque revelou a preocupação dos docentes em relação à sua formação continuada, mesmo estando habituados com a rotina profissional. Os docentes com tempo menor de docência representaram 37,20\%. De acordo com Silva (2000) a formação continuada deve assegurar complemento, aprofundamento e atualização de conhecimentos e de competências profissionais. Assim, segundo Sampaio (2016), esses atributos serão acrescentados à profissionalização do docente, e intervirão frente às exigências de um mundo competitivo, atualmente fundamentado na evolução da ciência e tecnologia, nas transformações econômico-sociais, pelo fenômeno da globalização, e pela extrema concorrência no mercado de trabalho.

Dentre as motivações que levaram o egresso a cursar pós-graduação em nível de mestrado, a opção aprimoramento técnico-científico foi a mais mencionada, sendo citada por $28,60 \%$ dos entrevistados. A seguir foram mencionadas as opções evolução na carreira $(23,50 \%)$ e melhor remuneração (20,20\%) (Quadro 1). Estes dados aproximam-se bastante dos observados por Sampaio (2016), que investigando o perfil motivacional de 51 egressos de mestrado em Educação Agrícola na área de Ensino em Educação e Gestão, docentes/técnicos de Institutos Federais do Brasil e bolsistas de Demanda Social da Coordenação de Aperfeiçoamento de Pessoal de Nível Superior (CAPES), citou como principais motivações as variáveis aprimoramento técnico-científico (62,74\%), satisfação pessoal $(60,78 \%)$ e melhor remuneração $(58,82 \%)$. Gonçalves (2001), trabalhando com egressos da área de Educação, relatou que 38,74\% elegeram o aprimoramento da atividade profissional como motivo principal para realizar o mestrado, com sequenciamento para a necessidade de ampliar os conhecimentos $(25,23 \%)$ e a qualificação para a docência (23,42\%). Estevam e Guimarães (2011) comentaram em seus estudos, que os três aspectos mais relevantes são busca pela carreira docente, aprimoramento profissional e desejo de realizar pesquisa. Mencionaram ainda, que a procura por um melhor aprimoramento se deve à consciência acerca das lacunas em suas formações, o que os faz buscar novos saberes e aprofundar 


\section{Fusm Eulloahá}

ISSN: 1984-6444 | http://dx.doi.org/10.5902/1984644435565

conhecimentos. Conforme já relatado, são muito escassos na literatura consultada dados sobre egressos de mestrado da Educação Agrícola, principalmente da área de Ensino dos Saberes Técnicos, e com os sujeitos aqui estudados, mas acredita-se que a escolha pela motivação melhor elencada se deva a que esses profissionais já possuem carreira definida, com boa remuneração, maior maturidade, e como citado pelos autores acima, desejando apenas tapar lacunas em sua expertise.

Com referência ao apoio da instituição de origem durante o período do mestrado, 83,30\% dos egressos mencionaram terem sido apoiados, $11,00 \%$ responderam terem sido apoiados parcialmente e 5,70\% não terem sido apoiados (Quadro 2). O PPGEA foi criado em 2003, com o propósito de capacitar profissionais da educação das Escolas Agrotécnicas e Técnicas Federais, Centros Federais de Educação Tecnológica e Institutos Federais, na área de Educação Agrícola, Técnica e Tecnológica, sendo prontamente reconhecido e viabilizado com recursos do Ministério da Educação. Com o advento da Lei nำ 11.892, de 29 de dezembro de 2008, que instituiu a Rede Federal de Educação Profissional, Científica e Tecnológica, as instituições citadas foram agrupadas e passaram a se denominar Instituto Federal de Educação, Ciência e Tecnologia (IFECT), órgão presente em diversos estados do país, e para o qual o PPGEA disponibiliza sua assistência na capacitação acadêmica dos gestores, docentes e técnicos. Atualmente o Programa faz convênio com diversos desses institutos e esses garantem o apoio à qualificação de seus profissionais (BRASIL, 2008; PPGEA, 2018).

Em relação à subárea de conhecimento elegida durante 0 curso, a predominância foi de Ensino em Meio Ambiente (39,00\%), seguida pela de Ensino em Agroindústria (22,00\%). As subáreas de Ensino em Produção Animal e Ensino em Produção Vegetal somaram juntas 39,00\%, individualmente abaixo das outras duas citadas (Quadro 2). Através desses dados, foi possível conhecer a eleição dos egressos nas quatro subáreas representativas dos Saberes Técnicos do PPGEA.

Referente ao motivo da escolha do PPGEA para realização do mestrado, $22,20 \%$ dos egressos elegeram a relação entre o conteúdo programático do curso e o trabalho como a primeira opção, 13,90\% a oportunidade de conciliação com o trabalho e 13,90\% a oportunidade de realização do mestrado (Quadro 2). Isso leva a 


\section{T usm Eutoraba}

ISSN: 1984-6444 | http://dx.doi.org/10.5902/1984644435565

refletir, que a primeira opção parte da premissa de que os indivíduos, provindos da docência nas subáreas do Ensino dos Saberes Técnicos em atividades agrícolas de Institutos Federais brasileiros, visualizaram que através do conteúdo programático oferecido pelo Programa, poderiam almejar contribuições em seu conhecimento para além daquele até então adquirido.

Quadro 2 - Perfil dos egressos do PPGEA/UFRRJ, da área de Ensino dos Saberes Técnicos, docentes dos Institutos Federais brasileiros, em seus indicadores, no decorrer do curso: licença profissional para cursar o mestrado; subárea de conhecimento selecionada; motivos que levaram à escolha do PPGEA; atendimento das expectativas de formação dos mestrandos; domínio e atualização dos professores do Programa; e, modalidade de ensino que atuavam.

\begin{tabular}{l|c}
\hline \multicolumn{1}{c|}{ Indicadores } & $\%$ \\
\hline Licença profissional & 83,30 \\
Apoio total & 11,00 \\
Apoio parcial & 5,70 \\
Sem apoio & \\
\hline Subárea de conhecimento selecionada & 39,00 \\
Ensino em Meio Ambiente & 20,00 \\
Ensino em Produção Animal & 22,00 \\
Ensino em Agroindústria & 19,00 \\
Ensino em Produção Vegetal & 22,20 \\
\hline Motivação para escolha do PPGEA & 13,90 \\
Relação entre conteúdo programático e trabalho & 13,90 \\
Conciliação com o trabalho & 11,10 \\
Oportunidade de realização do mestrado & 8,30 \\
Boas referências & 5,60 \\
Perfil do curso & 2,80 \\
Área de interesse & 2,80 \\
Flexibilidade & 19,40 \\
Recomendações de egressos & \\
Outras (abaixo de 2,00\%) & 83,30 \\
\hline Atendimento das expectativas & 16,70 \\
Plenamente alcançadas & \\
Parcialmente alcançadas & 97,00 \\
\hline Domínio e atuação dos professores & 3,00 \\
Domínio elevado & 48,20 \\
Domínio regular & 35,70 \\
\hline Modalidade de ensino que atuavam & 16,10 \\
Ensino Médio & \\
Ensino Superior & \\
Educação de Jovens e Adultos & \\
\hline
\end{tabular}

Fonte: Autores.

As outras duas opções melhores elencadas estão diretamente relacionadas à Pedagogia de Alternância e à organização das semanas de formação, adotadas pelo Programa, onde a ausência na instituição de origem não é tão prejudicial quanto um 


\section{Fusm Eulloahâ}

ISSN: 1984-6444 | http://dx.doi.org/10.5902/1984644435565

afastamento integral para cursar o mestrado clássico. Sampaio (2016) citou relatos de egressos do PPGEA da área de Ensino em Educação e Gestão, que exaltaram a metodologia aplicada pelo Programa, a qual possibilitou a junção entre estudo e trabalho. Em uma das falas, um egresso citado comentou: “... A possibilidade de fazer mestrado na metodologia utilizada pelo Programa é importante pois possibilita que os professores da rede possam se capacitar, sem afastar do trabalho".

A Pedagogia da Alternância é uma metodologia de ensino adotada pelo programa, onde as atividades acadêmicas acontecem alternadamente entre a sede do programa (UFRRJ) (e/ou seus pólos de formação) e a instituição de origem do mestrando. Desta forma, o PPGEA se desloca entre os centros de formação e a instituição do candidato, aonde dificilmente a formação continuada habitual chegaria. O não afastamento do docente de sua principal atividade, e a sua não descontextualização da região e de seu ambiente de trabalho, favorece no sentido de que os conceitos, conhecimentos e modelos novos, discutidos e apresentados pelo Programa, sejam inseridos e testados imediatamente dentro de sua realidade. As semanas de formação mencionadas se traduzem em períodos integrais de atividades, que são concentrados entre 30 ou 45 dias, possibilitando assim conciliar o estudo com o trabalho, no que concerne a um menor afastamento (PPGEA, 2018).

Ao serem questionados acerca da satisfação em suas expectativas, 83,30\% responderam que foram plenamente alcançadas e $16,70 \%$ que foram parcialmente alcançadas (Quadro 2). A opção não foram alcançadas não obteve citação. Podemos inferir então, que o Programa tem atingido sua meta, que é promover a formação e capacitação de profissionais de Educação Agrícola, para que possam desenvolver, na plenitude de suas potencialidades e possibilidades, as diferentes competências e saberes inerentes e próprios à função docente (PPGEA, 2018). Segundo Piéron (1996), expectativa se traduz em uma atitude de espera com certo grau de esperança. Explicando melhor, é o grau de êxito, ou de eficiência, que se deseja e espera atingir em uma determinada ação (SIMÕES, 2008).

Relatando sobre o domínio e atuação dos professores do Programa quanto à realidade profissional do docente/mestrando, 97,00\% dos egressos alegaram elevado domínio, enquanto 3,00\% consideraram domínio regular (Quadro 2). De 


\section{त Gutirahá}

ISSN: 1984-6444 | http://dx.doi.org/10.5902/1984644435565

acordo com Estevam (2007), a presença de bons profissionais com domínio e competência, evidencia a qualidade de um curso oferecido. Para Monteiro (2004, p. 112), dentre os atributos inerentes a um docente qualificado estão formação compatível com as especificidades do programa, capacidade didática, comunicação verbal adequada, aptidão para liderar pessoas e atenção às dificuldades dos alunos. Assim comenta: “... Verifica-se a presença de qualidade nos programas de pósgraduação quando seus professores apresentam adequada capacidade didática e científica". Diante do grande percentual de egressos que elogiaram a qualidade dos docentes do Programa, conclui-se que o PPGEA, neste indicador, está bem direcionado, podendo inclusive intentar melhores níveis quando da avaliação da CAPES. Atualmente o curso possui conceito 3 perante essa instituição, mas muito se tem feito para um melhor enquadramento, e o emprego de profissionais gabaritados, demonstra uma conduta em busca de tal meta.

Em correspondência às modalidades de ensino em que o egresso atuava, as respostas seguiram às relacionadas pela Lei de Diretrizes e Bases da Educação Nacional número 9.394/96 (BRASIL, 1996). Assim, pôde-se observar que os respondentes se dividiam entre o Ensino Médio (48,20\%), Ensino Superior (35,70\%) e Educação de Jovens e Adultos (16,10\%) (Quadro 2). Dentre estes, ficou estabelecido que a grande maioria $(40,00 \%)$ lecionava para cursos técnicos em Agropecuária e Zootecnia. Os Institutos Federais brasileiros constituem instituição de educação superior, básica e profissional, pluricurricular e multicampi, especializada na oferta de educação profissional e tecnológica nas diferentes modalidades de ensino, com base na conjugação de conhecimentos técnicos e tecnológicos às suas práticas pedagógicas (IFECT, 2010).

Inquirindo sobre a contribuição, através da formação no PPGEA, em sua atuação como docente, as respostas puderam ser classificadas como totalmente satisfatória $(44,40 \%)$, satisfatória $(47,20 \%)$ e parcialmente satisfatória $(8,40 \%)$ (Quadro 3). O grupo de pessoas que julgou como parcialmente satisfatória não justificou o motivo pelo qual escolheu esta resposta. Não foram contabilizadas citações insatisfatórias. Novamente infere-se que o Programa tem atingido sua meta, promovendo a qualificação de profissionais da área de Educação Agrícola, e no 


\section{U Lism Eutoraba}

ISSN: 1984-6444 | http://dx.doi.org/10.5902/1984644435565

caso desta pesquisa, docentes de Institutos Federais brasileiros, o que pode ser reconhecido através do julgamento dos participantes, no qual 100,00\% demonstraram algum nível de satisfação na contribuição do Programa em sua atuação profissional.

Quadro 3 - Perfil dos egressos do PPGEA/UFRRJ, da área de Ensino dos Saberes Técnicos, docentes dos Institutos Federais brasileiros, em seus indicadores, após conclusão do curso: contribuição do PPGEA para a atuação como docente; lotação do egresso; continuidade na formação acadêmica; mudanças ocorridas; função no Instituto Federal em consonância com a sua qualificação profissional; atividades que desenvolve além das atividades de docência; e, orientação de alunos em Iniciação Científica.

\begin{tabular}{l|c}
\hline \multicolumn{1}{c|}{ Indicadores } & $\%$ \\
\hline Contribuição do PPGEA na atuação como docente & 44,40 \\
Totalmente satisfatória & 47,20 \\
Satisfatória & 8,40 \\
Parcialmente satisfatória & \\
\hline Lotação após passagem pelo PPGEA & 89,00 \\
Permanecem na mesma instituição & 11,00 \\
Foram distribuídos para outras & \\
\hline Continuidade na formação acadêmica & 44,50 \\
Sim & 62,50 \\
- Doutorado & 6,30 \\
- Outro mestrado & 18,80 \\
- Master in Business Administration (MBA) & 12,40 \\
- Especialização & 55,60 \\
Não & 80,00 \\
- Não responderam o motivo & 15,00 \\
- Aguardo de aprovação & 5,00 \\
- Questões pessoais & 25,40 \\
\hline Mudanças após realização do curso & 33,30 \\
Maior confiança ao lecionar & 41,30 \\
Melhor remuneração & \\
Melhor conhecimento técnico & 89,00 \\
\hline Função em consonância com qualificação & 8,00 \\
Existência de consonância & 3,00 \\
Não existência & \\
Não responderam & 11,10 \\
\hline Atividades além da docência & 22,20 \\
Direção/Coordenação & 19,40 \\
Pesquisa e extensão & 5,60 \\
Orientação de projetos & 13,90 \\
Supervisão de estágio & 13,90 \\
Nenhuma & 5,5 \\
Coordenação de Eixo Tecnológico & 8,4 \\
Membro do NAPNE & \\
Outras & 61,10 \\
\hline Orientação de alunos & 38,90 \\
Sim & \\
Não & \\
\hline Fonte:Autos & \\
\hline
\end{tabular}

Fonte: Autores. 


\section{Fusm EUtrathâ}

ISSN: 1984-6444 | http://dx.doi.org/10.5902/1984644435565

Relatando sobre a lotação do egresso após a conclusão do mestrado no PPGEA, os resultados apresentados revelaram que $89,00 \%$ dos docentes permaneceram na mesma instituição após a titulação, e cerca de 11,00\% foram distribuídos para outras (Quadro 3). Estevam e Guimarães (2011) observaram em seus estudos, realizados com egressos da área de Educação, que a maioria após concluir seu aprimoramento, retornou à instituição de origem. Segundo os autores, esse retorno às atividades habituais, se deve às políticas universitárias atuais de cunho neoliberal, marcadas pela contenção de despesas e baixo investimento, onde a contração de estudantes de pós-graduação para ministrarem aulas por menores salários, em comparação àqueles que seriam despendidos se fosse admitido um professor realmente habilitado, provoca a não abertura de novas vagas em instituições, e consequentemente a não contratação de profissionais, agora mais gabaritados para tais funções. Os autores mencionaram Cusinato (1987), que relatou que professores em efetivo exercício do magistério e possuidores de curso superior por uma universidade pública, se mostram a cada dia mais ansiosos de prestar concurso para ocupar cargos que o tirem da sala de aula. Dessa forma, infere-se nesta pesquisa, em concordância com os autores citados, que a permanência dos egressos na mesma instituição, pode estar, entre outras premissas, vinculada à falta de oferta por outras, para uma ascensão profissional ambicionada.

Sobre a continuação dos estudos após a conclusão do mestrado, 44,50\% dos egressos responderam positivamente e 55,60\% negativamente (Quadro 3). Dentre os que continuaram a formação, $62,50 \%$ realizaram o doutorado, $12,40 \%$ deram prosseguimento aos estudos através de especializações e 6,30\% realizaram outro mestrado. A continuação dos estudos através de Master in Business Administration(MBA), modalidade esta considerada como especialização lato sensu e fortemente voltada para a prática profissional, também foi mencionada, somando $18,80 \%$. Quando questionados em relação ao motivo de não prosseguirem com os estudos, $80,00 \%$ dos egressos se eximiram de justificativas, 15,00\% estavam no aguardo de aprovação pelos programas de pós-graduação para ingresso no doutorado, e 5,00\% não deram continuidade por questões pessoais. Lôrdelo et al. 


\section{Fusm Eulloahá}

ISSN: 1984-6444 | http://dx.doi.org/10.5902/1984644435565

(2013) analisando o perfil de 153 egressos do curso de mestrado da Faculdade de Educação da Universidade Federal da Bahia, onde $74,20 \%$ dos pesquisados eram vinculados à educação pública, estabeleceram que 52,90\% não deram continuação aos estudos após o término do curso. Sampaio (2016) trabalhando com egressos da área de Educação e Gestão, do PPGEA/UFRRJ, provenientes de Institutos Federais nacionais e Demanda Social da CAPES, relataram que $64,71 \%$ dos pesquisados não deram continuidade à formação acadêmica. Concordando com as opiniões desse último autor, dispostas em seus estudos, nesta pesquisa infere-se que a não continuidade na formação tenha ocorrido entre outros fatores, pela falta de oportunidade oferecida a um público residente em lugares atingidos pela desigualdade regional e/ou profissional, por cursos de pós-graduação tradicionais que não os qualificariam na sua atividade acadêmica, pela falta de apoio institucional e pelo acúmulo de responsabilidades no trabalho e na família.

Sobre as mudanças ocorridas após a conclusão do curso de mestrado, $41,30 \%$ dos egressos relataram terem adquirido melhor conhecimento técnico, $33,30 \%$ melhor remuneração e 25,40\% maior confiança ao lecionar (Quadro 3). Segundo Oliverio (2014), o conhecimento conquistado pelo docente na formação se traduz no desenvolvimento da capacidade de observação, de registro, de documentação, de análise, de síntese, entre outras, que são importantíssimas para o desempenho da docência. O mesmo autor observa que o mestrado propicia uma visão diferenciada da realidade, mais problematizadora, menos incauta e mais fundamentada; influenciando na prática desses docentes, na maneira de perceber e intervir na aprendizagem do aluno e de ajudá-lo na construção dos seus conhecimentos. Comentando sobre a questão remuneração, segunda variável mais citada, Mendes et al. (2010) pesquisando egressos de curso de mestrado em Ciências e Saúde, docentes de Instituições de Ensino Superior, elucidaram que essa era proveniente da obtenção de progressão financeira e funcional devido à titulação. Os autores afirmam que a progressão é prevista, pois há uma tendência de que, quanto mais graus de formação um indivíduo possui, maior a renda do seu trabalho. Silveira (2012) relatou que retornando às suas atividades, após conclusão do mestrado, o docente leva consigo uma nova atitude, um outro fôlego e uma 


\section{IFs" Euttagha}

ISSN: 1984-6444 | http://dx.doi.org/10.5902/1984644435565

mudança no modo de ver e conduzir sua prática pedagógica, ainda, no relacionamento com seus pares e com a instituição como um todo, frutos do amadurecimento e da experiência adquirida.

Analisando as respostas acerca da existência ou não de consonância entre a função exercida na instituição empregadora e a qualificação profissional, 89,00\% avaliaram positivamente, $8,00 \%$ disseram não existir, e cerca de 3,00\% não responderam (Quadro 3). Existiram docentes que mencionaram dupla ocupação, entre docência e coordenação do curso; neste caso, a questão foi entendida como em consonância com a docência e contrária à coordenação. Araújo (2007), comentando sobre acúmulo/desvio de função, elucidou que as consequentes alterações na organização escolar tem resultado em uma sobrecarga nas atividades dos docentes, reestruturando seu trabalho e forjando uma nova identidade, onde o professor se vê frente ao desafio de responder a exigências que estão além de sua formação, desempenhando funções de agente público, assistente social, psicólogo, entre outras. Não foi o que aconteceu nesta pesquisa, onde a quase unanimidade dos entrevistados responderam afirmativamente à existência de concordância entre a qualificação e a função exercida, aqui docência.

Investigando se os egressos desenvolviam atividades além da docência, contabilizou-se resposta positiva de $86,10 \%$ dos respondentes, predominando nesse caso, a pesquisa e a extensão, visto serem inerentes a sua prática. No entanto, ainda foi possível encontrar uma parte de egressos que afirmaram exercer somente atividades de ensino em sala de aula (13,90\%) (Quadro 3). Segundo Libâneo (2005), o conceito atual de docência não se constitui apenas de um ato restrito de ministrar aulas, mas sim, passa a ser entendido na amplitude do trabalho pedagógico, onde toda a atividade educativa desenvolvida em espaços escolares e não-escolares deve ter o entendimento de docência. Salienta ainda, que as novas exigências consistem em um docente que tenha qualificação profissional específica e tenha como prática não somente a docência, mas também a pesquisa. A Lei número 11.301/06 destacou que, no exercício do magistério, também se compreende atividades não docentes exercidas por professores em estabelecimento de ensino de todo país (BRASIL, 2006). 


\section{Autตaดูão}

ISSN: 1984-6444 | http://dx.doi.org/10.5902/1984644435565

Foi indagado aos egressos sobre 0 ato de orientação a alunos em processo de iniciação científica, e a resposta somou uma porcentagem positiva de $61,10 \%$ (Quadro 3), sendo essa prática direcionada a projetos locais, organização de semanas acadêmicas e Programa Institucional de Bolsa de Iniciação Científica (PIBIC) aplicado ao ensino técnico e superior. Wolff (2007) elucidou que um bom orientador precisa ter habilidade para auxiliar seu aluno ao longo das etapas de uma pesquisa, traduzidas pela definição do tema, contextualização e delimitação do problema, e definição dos objetivos. E a partir do tema e dos objetivos propostos, direcionar o orientando nas etapas metodológicas à frente, entre elas, local do estudo, seleção dos sujeitos, escolha do tipo de pesquisa, da metodologia apropriada e dos instrumentos a serem utilizados. Adicionalmente soma-se ao orientador a competência pela temática, os valores éticos e o bom relacionamento interpessoal. O mesmo autor salientou que aprende-se a ser orientador a partir da experiência de ter realizado pesquisa, dessa forma, enfatiza-se a contribuição do mestrado no PPGEA na competência desses egressos, principalmente quando eles afirmaram 100,00\% de satisfação na colaboração em sua atuação como docente e no alcance de suas expectativas. Entende-se aqui, que ao expressar tais falas, os egressos unem as suas atividades da docência a orientação de alunos.

Sobre o estímulo à produção científica após a realização do mestrado, $78,00 \%$ dos entrevistados alegaram esse positivamente (Quadro 4), mencionando o envolvimento em projetos, publicações, e melhora na capacidade interpretativa de projetos. A maior parte daqueles que responderam negativamente declarou não se sentirem incentivados ou não terem tempo para dedicação. Estevam, em 2007, analisando egressos de mestrado em Educação, constatou que a falta de produção científica provinha da necessidade desses sujeitos em aliar trabalho, pesquisa e coleta de dados em curto espaço de tempo, além da falta de incentivo e do baixo valor das bolsas, que desestimulavam os indivíduos a deixarem seus vínculos empregatícios e consequentemente sua remuneração, para se dedicarem mais à pesquisa. Certamente, neste estudo, concordamos com esse autor, quando mencionou que seriam estes os fatores cruciais de entrave nessa direção. 


\section{Wusm Eutoraba}

ISSN: 1984-6444 | http://dx.doi.org/10.5902/1984644435565

Questionando sobre a publicação dos resultados de sua dissertação após defesa, 60,00\% dos egressos relataram terem publicado (Quadro 4). Estevam (2007) e Coelho e Silva (2017), em suas pesquisas, verificaram percentuais de $39,00 \%$ e $50,00 \%$ de publicações, respectivamente.

Quadro 4 - Perfil dos egressos do PPGEA/UFRRJ, da área de Ensino dos Saberes Técnicos, docentes dos Institutos Federais brasileiros, em seus indicadores pró desempenho científico: estímulo à produção após o mestrado; publicação sobre sua dissertação em periódicos, livros ou outros; e, participação em eventos.

\begin{tabular}{l|c}
\hline \multicolumn{1}{c|}{ Indicadores } & $\%$ \\
\hline Estímulo à produção científica & 78,00 \\
Houve estímulo positivo & 22,00 \\
Não houve estímulo & \\
\hline Publicação dos resultados da dissertação & 60,00 \\
Publicaram & 40,00 \\
Não publicaram & \\
\hline Participação em eventos & 50,00 \\
Congressos & 14,00 \\
Feiras e eventos nas próprias instituições & 36,00 \\
Não participaram & \\
\hline
\end{tabular}

Fonte: Autores.

Gadotti (1991) atribuiu a falta de publicação aos programas de pósgraduação, onde os mestrandos vão para assistirem aulas e completarem créditos, não conseguindo depois escrever um artigo porque não se exercitaram durante os cursos, no caso, nas disciplinas. Salientou ainda, que eles precisam ter uma vida acadêmica intensa, por meio de participação em eventos a nível nacional e internacional, e a nosso entender, certamente para exercitar a prática metodológica e a escrita científica. Informações sobre publicação é muito importante, porque reflete diretamente na avaliação da comissão da CAPES, ao estabelecer o conceito final dos Programas. Esta avaliação compreende um conjunto de fatores e as publicações apresentam considerável influência na pontuação. Programas que permanecem com conceito 3 em três avaliações trienais consecutivas, necessitam reformular suas propostas pedagógicas, ou podem ser encerrados.

No intuito de saber da participação dos egressos em algum evento científico após a conclusão do mestrado, elaborou-se uma questão, e entre os respondentes, $50,00 \%$ afirmaram que sim, 36,00\% que não, e 14,00\% disseram terem participado 


\section{Autดaคูão}

ISSN: 1984-6444 | http://dx.doi.org/10.5902/1984644435565

de eventos menores, tais como, feiras nas instituições em que são lotados (Quadro 4). Figueredo et al.(2016) comentando sobre a importância de eventos científicos para a formação docente, explicitaram que os mesmos se apresentam como fonte essencial para a busca de novos conhecimentos, permitindo o enriquecimento do saber acadêmico, e ampliando sua cultura, formação acadêmica e profissional.

Encerrando, foi formulada uma questão aberta, com intuito de obter um parecer pelos egressos pesquisados, sobre o que consideravam importante mencionar a respeito da atuação do programa. Sendo assim, representando as opiniões da maioria dos respondentes, dispôs-se a seguir algumas falas:

R01 (Respondente 01): “... O PPGEA é uma grande oportunidade para professores da rede federal, um curso dinâmico e de proposta inovadora".

R02: "... Considero que a pedagogia da alternância e a interdisciplinaridade propostas pelo PPGEA oportunizam formação única aos mestrandos, ao menos à época em que cursei".

R03: "... Acho que o PPGEA deveria ter programa de doutorado".

R04: “... Este mestrado oportunizou a reciclagem de docentes que se encontravam totalmente afastados do meio acadêmico, em virtude da dificuldade de se conseguir afastamento integral para qualificação. Os módulos concentrados tornaram possível e viável a qualificação e a permanência das atividades docentes".

R05: "... O programa é muito importante para a rede federal de educação profissional e deve ser ampliado ao nível de doutorado".

R06: "... Que foi uma pena não ter formado nenhuma turma em meu campus, pois era sempre mais uma oportunidade para outras pessoas".

R07: “... O PPGEA foi o grande resgate dos docentes das antigas escolas agrotécnicas".

R08: “... Que o PPGEA me proporcionou momentos maravilhosos além dos estudos, pois a paixão que os criadores demonstravam me inspirou a ser uma profissional melhor".

R09: “... Que os institutos entendam a dinâmica do PPGEA e se aproximem mais da UFRRJ/PPGEA".

R10: “... Gostaria de acrescentar que os colegas que forem cursar o mestrado 


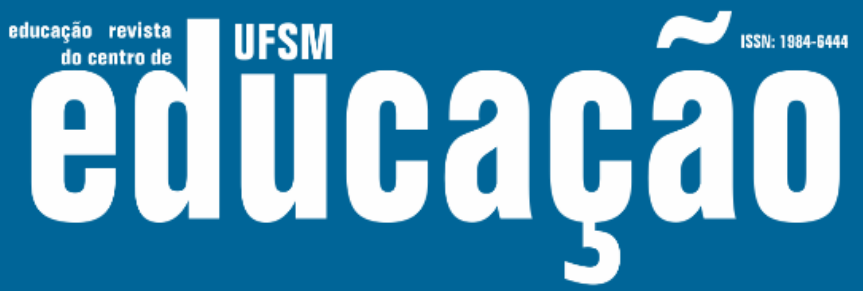

ISSN: 1984-6444 | http://dx.doi.org/10.5902/1984644435565

no PPGEA devem aproveitar o máximo, pois isso vai acrescentar muito na sua carreira como docente".

R11: "... Dizer aos mestrandos que aproveitem ao máximo que puder todas as oportunidades dentro do curso".

De forma geral, os egressos participantes desta pesquisa avaliaram positivamente a caminhada pelo PPGEA e sugeriram a abertura do curso de doutorado, visto a experiência durante o mestrado ter sido válida e construtiva. As diversas falas revelaram a satisfação dos egressos para com o PPGEA/UFRRJ, o que nos remete à reflexão da abrangência e importância social deste programa de pós-graduação no território brasileiro.

O curso de doutorado ainda não foi submetido às Propostas para Cursos Novos da CAPES, em virtude do curso de mestrado apresentar conceito 3 na avaliação. A maior pendência para o aumento do conceito é o número baixo de publicações em revistas conceituadas, apesar do grande número de defesas ao longo dos 10 anos de existência do curso.

\section{Considerações Finais}

A proposta da presente pesquisa foi a de caracterizar o perfil do egresso de mestrado do PPGEA/UFRRJ, da área de Ensino dos Saberes Técnicos, composto por docentes dos Institutos Federais de Educação, Ciência e Tecnologia do Brasil. Também foram realizadas investigações da inferência da formação no mestrado sobre a prática pedagógica exercida pelo docente, e do comprometimento do Programa com a construção do conhecimento de seu egresso.

A pesquisa apresentou foco em 117 egressos, que eram docentes exclusivos de Institutos Federais brasileiros, e desses apenas 30,77\% participaram, respondendo aos questionários enviados. A utilização de questionários virtuais promove a comunicação de maneira mais instantânea com o sujeito a ser pesquisado, no entanto, cabe a ele decidir por responder ou não. Nesta pesquisa os questionários formaram a metodologia estabelecida para alcançar os objetivos propostos. 


\section{Autดaคูão}

ISSN: 1984-6444 | http://dx.doi.org/10.5902/1984644435565

Primeiramente, através da respostas obtidas, pode-se traçar o perfil dos egressos participantes desta pesquisa:

1) a distribuição por região geográfica evidenciou que a maior parte era oriunda da região Sudeste;

2) sua proveniência era quase que totalmente das áreas de graduação em Ciências Agrícolas e Ciências Biológicas, com predominância dos cursos de Licenciatura;

3) a maioria apresentava mais de 15 anos de docência;

4) o interesse pela formação continuada ao nível de mestrado foi motivado pelo aprimoramento técnico-científico, pela evolução na carreira docente e pela melhor remuneração;

5) lecionavam para modalidades de ensino variadas, mas com maior predominância para o Ensino Médio;

6) além do ensino, atuavam em atividades de pesquisa e extensão e na orientação de projetos. Uma pequena quantidade exercia exclusivamente a docência;

7) ○ grupo de docentes que atuava na orientação de projetos procurava estimular o envolvimento de alunos em programas de Iniciação Científica, projetos locais e organização de eventos;

8) após passagem pelo PPGEA a grande maioria permaneceu na sua instituição de origem, exercendo a mesma função anterior;

9) sobre as mudanças ocorridas após a conclusão do Programa, basicamente relataram aquisição de melhor conhecimento técnico, melhor remuneração e maior confiança ao lecionar, nessa ordem;

10) um maior número deu prosseguimento à sua formação, matriculando-se em Programas de Doutorado; outros tantos, em novos mestrados, e em especializações diversas, tais como MBA e lato sensu;

11) com respeito à qualificação em consonância com a função exercida na instituição empregadora, quase que a totalidade informou conexão.

Analisando as respostas dos docentes em função da inferência da formação no PPGEA sobre a prática pedagógica exercida, pôde-se estabelecer essa como 


\section{TH Wu Eutbapga}

ISSN: 1984-6444 | http://dx.doi.org/10.5902/1984644435565

considerável, visto que todos os egressos participantes da pesquisa mencionaram algum grau de satisfação, sem nenhuma citação contrária. Dentre as contribuições promovidas pelo Programa à atividade docente, foram citadas o melhor conhecimento técnico e a maior confiança ao lecionar.

Finalizando, pode-se inferir que o PPGEA tem cumprido com sua meta, com respeito à construção do conhecimento e capacitação de seu egresso, principalmente quando a totalidade dos respondentes afirmou ter atingido suas expectativas, plena e parcialmente, durante a realização do curso. Em algumas falas os egressos demonstraram gratidão por estarem incluídos na história do PPGEA, sugerindo inclusive a abertura da modalidade de Doutorado. Além disso, a contribuição por promover a qualificação de docentes afastados do meio acadêmico por questões de dificuldade de liberação para cursar o mestrado também foi exaltada.

$\mathrm{Na}$ análise da literatura há poucos estudos que se propõem a avaliar o contexto aqui abordado, relativo ao acompanhamento de egressos de mestrado stricto sensu na área de Educação Agrícola, e ainda docentes de Institutos Federais nacionais; mas, dentro desse universo irrisório de publicações, procurou-se discutir e opinar sobre os diversos indicadores aqui convencionados.

\section{Referências}

ARAÚJO, Samara Carla Lopes Guerra. Ser professor coordenador pedagógico: sobre o trabalho docente e sua autonomia. 2007, 199f. Dissertação (Mestrado em Educação) - Universidade Federal de Minas Gerais, Belo Horizonte.

BANNAN, K. J. Companies save time, money with online surveys. B to B, v. 88 , n. 6 , p. 1-2, jun. 2003.

BARDIN, Laurence. Análise de conteúdo. Lisboa: Edições 70, LDA, 2009.

BATISTA, Roberto Leme. A ideologia da nova educação profissional no contexto da reestruturação produtiva. São Paulo: Cultura Acadêmica, 2011.

BORTOLOZZI, Flávio; GREMSKI, Waldemiro. Pesquisa e pós-graduação brasileira assimetrias. Revista Brasileira de Pós-Graduação, Brasília, v. 1, n. 2, p. 35-52, nov. 2004. Disponível em: http://ojs.rbpg.capes.gov.br/index.php/rbpg/article/viewFile /39/36. Acesso em: 18 out. 2018. 


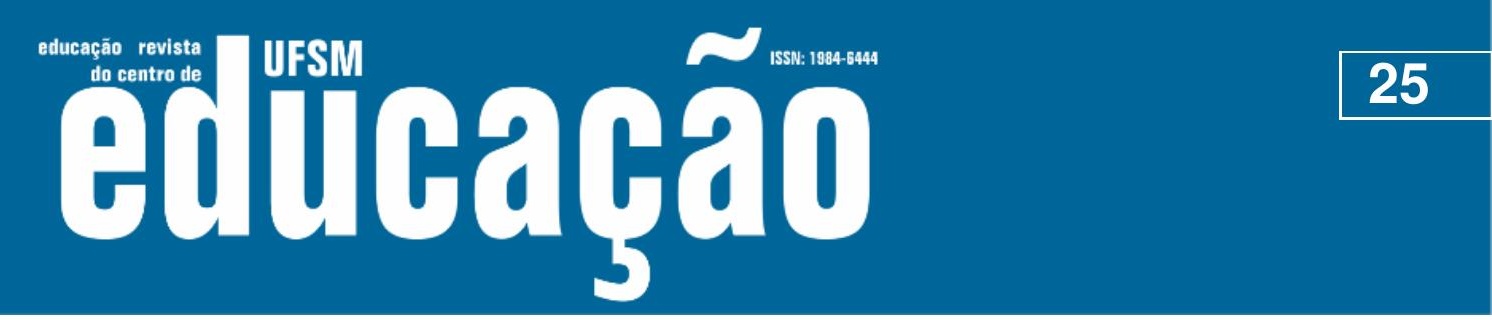

ISSN: 1984-6444 | http://dx.doi.org/10.5902/1984644435565

BRASIL. Lei n. ${ }^{\circ}$ 9.394, de 20 de novembro de 1996. Estabelece as diretrizes e bases da educação nacional. Diário Oficial da União, Brasília, seção 1, p. 27833, 1996.

BRASIL. Lei n. ${ }^{\circ} 11.301$, de 10 de maio de 2006. Define as funções do magistério. Diário Oficial da União, Brasília, seção 1, p. 2, 2006.

BRASIL. Lei n. ${ }^{\circ} 11.892$, de 29 de dezembro de 2008. Institui a Rede Federal de Educação Profissional, Científica e Tecnológica, cria os Institutos Federais de Educação, Ciência e Tecnologia, e dá outras providências. Diário Oficial da União, Brasília, seção 1, p. 1, 2008.

CHAER, Galdino; DINIZ, Rafael Rosa Pereira; RIBEIRO, Elisa Antônia. A técnica do questionário na pesquisa educacional. Evidência, Araxá, v. 7, n. 7, p. 251-266, mai. 2011. Disponível em: http://www.educadores.diaadia.pr.gov.br/arquivos/File/maio201 3/sociologia_artigos/pesqusia_social.pdf. Acesso em: 18 out. 2018.

COELHO, Maria Carlota de Rezende; SILVA, Janine Pereira. Acompanhamento de egressos como instrumento de gestão. Textos \& Contextos, Porto Alegre, v. 16, n. 2, p. 470-478, ago./dez. 2017. Disponivel em: http://revistaseletronicas.pucrs.br/ojs/in dex.php/fass/article/view/29514/16425. Acessoem: 4 out. 2018.

CRESWELL, John. Projeto de Pesquisa: métodos qualitativo, quantitativo e misto. 2. ed. Porto Alegre: Artmed, 2007.

CUSINATO, Ricardo. A formação do professor da área de Estudos Sociais. 1987, 233f. Tese (Doutorado em Educação) - Universidade Estadual de Campinas, Campinas.

DEMO, Pedro. Aprendizagem e novas tecnologias. Revista Brasileira de Docência, Ensino e Pesquisa em Educação Física, Cristalina, v. 1, n. 1, p. 53-75, ago. 2009.

ESTEVAM, Humberto Marcondes. Avaliação do perfil de egressos do Programa de Pós-Graduação Strictu Senso em Educação Escolar: impacto na formação docente e de pesquisador. 2007, 107f. Tese (Doutorado em Educação Escolar) Universidade Estadual Paulista, Araraquara.

ESTEVAM, Humberto Marcondes; GUIMARÃES, Selva. Avaliação do perfil de egressos do Programa de Pós-Graduação Stricto Sensu em Educação da UFU: impacto na formação docente e de pesquisador (2004-2009). Avaliação, Campinas, v. 16, n. 3, p. 703-730, nov. 2011. Disponível em: http://www.scielo.br/pdf/aval/v16n3 /v16n1a12.pdf. Acesso em: 4 out. 2018.

FIGUEREDO, Jucelir de Lima et al. A importância da participação dos estudantes do ensino superior em eventos científicos para sua formação acadêmica. In: CONGRESSO NACIONAL DE EDUCAÇÃO, 3., 2016, Natal. Anais...Natal: Centro Multidisciplinar de Estudos e Pesquisas, 2016. v. 1.

GADOTTI, Moacir. A pós-graduação em Educação. Campinas: Papirus, 1991. 


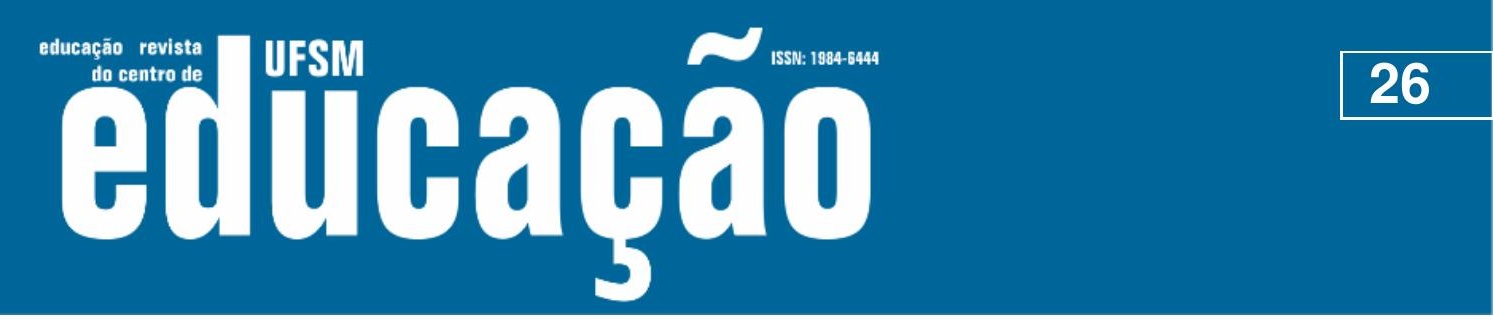

ISSN: 1984-6444 | http://dx.doi.org/10.5902/1984644435565

GARCIA, Fernanda Wolf. A importância do uso das tecnologias no processo de ensino-aprendizagem. Educação a Distância, Batatais, v. 3, n. 1, p. 25-48, jan./dez. 2013. Disponível em: file:///C:/Users/usuario/Downloads/sumario2\%20(2).pdf. Acesso em: 16 ago. 2018.

GIL, Antonio Carlos. Métodos e técnicas de pesquisa social. 6. ed. São Paulo: Atlas, 2008.

GODOY, Arilda Schmidt. Introdução à pesquisa qualitativa e suas possibilidades. Revista de Administração de Empresas, São Paulo, v. 35, n. 2, p. 57-63, mar./abr. 1995. Disponível em: http://www.scielo.br/scielo.php?script=sci_arttext\&pid=S003475901995000200008. Acesso em: 15 set. 2018.

GOMES, Rita de Cássia Medeiros. A formação dos professores no contexto atual. Revista de Educação, São Paulo, v. 14, n. 18, p. 103-125, mai. 2011. Disponível em: $\quad$ http://www.pgsskroton.com.br/seer/index.php/educ/article/viewFile/1722/1647. Acesso em: 25 set. 2018.

GONÇALVES, Daniel Infante Ferreira. Pesquisas de marketing pela internet: As percepções sob a ótica dos entrevistados. Revista de Administração Mackenzie, São Paulo, v. 9, n. 7, p. 70-88, nov./dez. 2008. Disponível em: http://editorarevistas.mackenzie.br/index.php/RAM/article/viewFile/201/201. Acesso em: 15 mai. 2018.

GONÇALVES, Elizabeth Moraes. Discípulos do grupo comunicacional de São Bernardo do Campo: Avaliação de uma experiência acadêmica. Comunicação \& Sociedade, São Bernardo do Campo, v. 23, n. 36, p. 13-32, jul./dez. 2001.

GUIMARÃES, Isac Pimentel et al. Avaliação da Pós-Graduação em Educação do Brasil: como superar a imprecisão que reina entre nós? Quaestio - Revista de Estudos em Educação, Sorocaba, v. 17, n. 1, p. 87-119, jun. 2015.

IFECT. Um novo modelo em educação profissional e tecnológica. Concepção e diretrizes. Brasília: Instituto Federal de Educação, Ciência e Tecnologia, Ministério da Educação, 2010.

LIBÂNEO, José Carlos. Pedagogia e pedagogos, para quê? 8. ed. São Paulo: Cortez, 2005.

LÔRDELO, José Albertino; NOGUEIRA, Renée Albagli; ROSA, Dora Leal. Meritocrática ou reparadora: uma discussão sobre a responsabilidade social da pósgraduação. Revista Entreideias, Salvador, v. 2, n. 1, p. 61-78, jan./jun. 2013. Disponível em: https://portalseer.ufba.br/index.php/entreideias/article/viewFile/6067/ 6554. Acesso em: 28 out. 2018.

MARCONI, Marina de Andrade; LAKATOS, Eva. Maria. Técnicas de pesquisa. 8. ed. São Paulo: Atlas, 2017a. 


\section{OF \\ ISSN: $1984-6444$

ISSN: 1984-6444 | http://dx.doi.org/10.5902/1984644435565

MARCONI, Marina de Andrade; LAKATOS, Eva Maria. Fundamentos de metodologia científica. 8. ed. São Paulo: Atlas, 2017b.

MENDES, Inês Roeder Nogueira et al. Análise do perfil dos mestrandos do Programa de Pós-Graduação em Ambiente e Sistemas de Produção Agrícola. Nucleus, Ituverava, v. 14, n. 1, p. 267-278, abr. 2017.

MENDES, Regina Ferraz et al. Percepção sobre o curso e perfil dos egressos do Programa de Mestrado em Ciências e Saúde da UFPI. Revista Brasileira de PósGraduação, Brasília, v. 7, n. 12, p. 82-101, jul. 2010.

MICHEL, Maria Helena Metodologia e pesquisa científica em ciências sociais. 2 . ed. São Paulo: Atlas, 2009.

MICROSOFT. Produtos. Excel. Disponível em: https://products.office.com/ptbr/home. Acesso em: 03 jul. 2018.

MONTEIRO, Luiz Antônio dos Santos A percepção de docentes e egressos sobre os componentes e atributos da qualidade nos programas de pós-graduação das engenharias nas universidades federais da região sul do Brasil. 2004, $198 \mathrm{f}$. Tese (Doutorado em Engenharia de Produção) - Universidade Federal de Santa Catarina, Florianópolis.

OLIVERIO, Vanessa Cristina Maximo Portella. Professores iniciantes: inserção nas redes de ensino e condições de trabalho desiguais. 2014, 263f. Tese (Doutorado em Educação) - Pontifícia Universidade Católica, Rio de Janeiro.

PARO, Vitor Henrique. A escola pública que queremos. In: CONFERÊNCIA ESTADUAL EXTRAORDINÁRIA DE EDUCAÇÃO, I., 2006, Curitiba. Anais...Curitiba: Sindicato dos Trabalhadores em Educação Pública do Paraná, 2006. p. 9-15.

PIÉRON, Henri. Dicionário de Psicologia. Rio de Janeiro: Editora Globo, 1996.

PPGEA. Portal do Programa de Pós-Graduação em Educação Agrícola. Disponível em: http://cursos.ufrrj.br/posgraduacao/ppgea/historia-do-ppgea/. Acesso em: 27 jun. 2018.

RICHARDSON, Roberto Jarry. Pesquisa social: métodos e técnicas. 4. ed. São Paulo: Atlas, 2018.

SAMPAIO, Marize Setubal. O perfil dos egressos do Programa de PósGraduação em Educação Agrícola da Universidade Federal Rural do Rio de Janeiro. 2016, 64f. Dissertação (Mestrado em Educação) - Universidade Federal Rural do Rio de Janeiro, Seropédica.

SANTOS, Humberto de Faria. Revoluções tecnológicas e sociedade. Academos, São Bernardo do Campo, v. 2, n. 2, p.57-68, jul./dez. 2006. 


\section{usm Fillagha}

ISSN: 1984-6444 | http://dx.doi.org/10.5902/1984644435565

SECTI. Boletim de indicadores em Ciência, Tecnologia e Inovação. Recife: Secretaria de Estado da Ciência, Tecnologia e Inovação, Governo do Estado de Pernambuco, 2015.

SELLES, Sandra Escovedo. Formação continuada e desenvolvimento profissional de professores de ciências: anotações de um projeto. Ensaio - Pesquisa em Educação em Ciências, Belo Horizonte, v. 2, n. 2, p.167-181, jul./dez. 2002. Disponível em: http://www.scielo.br/pdf/epec/v2n2/1983-2117-epec-2-02-00167.pdf. Acesso em: 17 out. 2018.

SILVA, Ana Maria Costa. A formação contínua de professores: Uma reflexão sobre as práticas e as práticas de reflexão em formação. Educação \& Sociedade, Campinas, v. 21, n. 72, p. 89-109, ago. 2000.

SILVEIRA, Clarice Santiago. A formação em pesquisa no mestrado em educação: contribuições para prática pedagógica e profissional de professores da educação básica. 2012, 197f. Dissertação (Mestrado em Educação) - Universidade Estadual do Ceará, Fortaleza.

SIMÕES, Aida de Jesus Correia. Motivações e expectativas profissionais dos estudantes de enfermagem - Estudo numa escola da área de Lisboa. 2008, 219f. Dissertação (Mestrado em Comunicação em Saúde) - Universidade Aberta, Lisboa.

WOLFF, Lillian Daisy Gonçalves. O papel do professor na orientação de trabalho científico. Cogitare Enfermagem, Curitiba, v. 12, n. 4, p. 413-415, out./dez. 2007.

\section{Correspondência}

Lucila Maria Teixeira Nunes - Universidade Federal Rural do Rio de Janeiro - BR 465 Km 07 - Campus Universitário - CEP23890-000. Seropédica, Rio de Janeiro, Brasil.

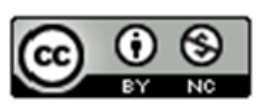

This work is licensed under a Creative Commons Attribution-NonCommercial 4.0 International (CC BY-NC 4.0) 